\title{
Transformação da periferia e novas formas de desigualdades nas metrópoles brasileiras: um olhar sobre as mudanças na produção habitacional
}

\author{
Transformation of the urban periphery and new forms \\ of inequality in Brazilian cities: a view on the recent \\ changes in housing production
}

Maria Beatriz Cruz Rufino

\begin{abstract}
Resumo
Este artigo tem como objetivo discutir as recentes transformações nas periferias das grandes metrópoles brasileiras, considerando a expansão da produção imobiliária nesses territórios, suportada em grande medida pelo lançamento do Programa Habitacional Minha Casa Minha Vida. Partindo de uma análise histórica e teórica, procuramos mostrar o deslocamento da primazia da contradição entre capital-trabalho, sob o domínio do capital industrial, para a primazia de uma contradição urbana, sob domínio do capital financeiro. Nossa hipótese é que a periferia, cuja formação foi caracterizada "trinômio casa própria-loteamento periférico-autoconstrução", consolida-se na atualidade como estratégia essencial na ampliação dos ganhos e na expansão da produção imobiliária. Essa estratégia de valorização do capital parece impor novas formas de desigualdades, que procuramos explorar.
\end{abstract}

Palavras-chave: financeirização; metrópole; periferia; mercado imobiliário.

\begin{abstract}
This article's objective is to discuss recent transformations in the periphery of Brazil's largest cities, considering the expansion of real estate in these territories, strongly supported by the Government's housing program Minha Casa Minha Vida. Using historical and theoretical analyses, we demonstrate the shift in the primacy of the contradiction between capital and labor, dominated by industrial capital, towards the primacy of an urban contradiction, dominated by financial capital. Our hypothesis is that the appropriation of the periphery has consolidated into an essential strategy in the amplification of gains and in the expansion of real estate. This strategy of capital appreciation seems to impose new forms of inequality, which we have attempted to explore here.
\end{abstract}

Keywords: financialization; metropolis; periphery; real estate market. 


\section{Introdução}

A primeira década do século XXI é marcada por uma intensificação da produção imobiliária no Brasil, manifestada pelo aumento do volume da produção e por forte valorização imobiliária. Em 2010, a valorização imobiliária alcançada foi de $23 \%$, representando a segunda maior taxa mundial (Cf. revista Exame, de 30 de maio de 2012). Um conjunto de trabalhos e pesquisas desenvolvidos recentemente (Royer, 2009; Fix, 2012; Shimbo, 2010; Rufino, 2012) mostram que esse quadro de intensificação da produção imobiliária das cidades brasileiras insere-se no movimento geral de convergência entre capital financeiro e imobiliário e repercute em mudanças estruturais na organização do setor imobiliário e na reconfiguração das cidades brasileiras.

No Brasil, a aproximação do capital financeiro ao setor imobiliário foi suportada, em grande medida, pela redefinição do marco regulatório do setor e pelo crescimento da oferta de financiamentos, a partir da importante recuperação das principais fontes de financiamento habitacional, organizadas pelo Estado no Sistema Financeiro Habitacional (SFH) e posteriormente reforçadas na implementação do Programa Habitacional Minha Casa Minha Vida.

Relacionado ao crescimento econômico do país, as tradicionais fontes do SFH - o Fundo de Garantia por Tempo de Serviço (FGTS) e o Sistema Brasileiro de Poupança e Empréstimos (SBPE) - começam a apresentar resultados excepcionais, configurando-se como base fundamental da expansão do setor, sendo responsáveis no ano de 2012 por cerca de 95\% do estoque de crédito habitacional (Mendonça e Sachsida, 2012).

Entre 2005 e 2010, a contratação de recursos para a habitação a partir da utilização do FGTS foi multiplicada em cerca de cinco vezes. Esse aumento foi ainda mais expressivo no caso do SBPE, em que os volumes contratados em 2010 superam em mais de dez vezes as contrações do ano de 2005.

Nesse cenário fortemente favorável à expansão do consumo da produção imobiliária, a abertura de capital das grandes incorporadoras se consolidou como uma nova possibilidade de captar recursos do mercado financeiro. Num primeiro ciclo de captação, entre 2005 e 2007, 25 empresas, predominantemente localizadas no eixo Rio-São Paulo, conseguiram captar cerca de 12 bilhões de reais, consolidando o setor imobiliário como uma importante área do mercado de capital financeiro e atraindo grande atenção de investidores estrangeiros, que chegaram a representar "mais de $75 \%$ desse volume dos capitais" (Rocha Lima Jr. e Gregório, 2008). Procurando ampliar seus investimentos, muitas dessas empresas passaram a se destacar por direcionar sua produção para a população de menor renda (Shimbo, 2010).

Essa nova estratégia do mercado imobiliário impulsionou um importante movimento de transformação e expansão das periferias das grandes metrópoles, cuja formação original, esteve particularmente relacionada ao intenso processo de urbanização da América Latina a partir dos anos 1960, sendo pautada pelo "trinômio casa própria-loteamento periférico-autocontrução" (Bonduki, 2004).

Tradicionalmente a produção imobiliária de mercado, principalmente concentrada nas áreas centrais, tendeu a reforçar a dicotomia 
entre centro equipado e territórios precariamente ocupados. Esses territórios precários contrastavam e valorizavam ainda mais os espaços mais bem servidos e mais equipados. Esse duplo movimento explicitava diferenças e levava a cidade a um rápido processo de expansão, pautado por baixa densidade e informalidade nas construções, que passou a ser descrito como sendo "um padrão periférico de crescimento urbano" (Bolaffi, 1979). Nesse contexto se fortaleceu uma visão segmentada e dual da urbanização, "onde uma produção organizada do espaço - moderna e industrial - se contrapunha a outro espaço, onde à apropriação desorganizada do lote se somava a produção precária da casa-própria por trabaIhadores" (Pereira, 2005).

É sobre essas periferias, que na atualidade se evidenciará a expansão da produção imobiliária de mercado, consubstanciando novas relações de produção das periferias. Esse movimento faz com que a forma de produção para mercado, dominante nos mecanismos de valorização, se torne também predominante no processo de urbanização. Em sua obra, a Produção Social do Espaço, Gottidiener (2007) já pontuava que a produção do espaço decorria não apenas dos processos econômicos, mas também e, mais especificamente, de uma articulação conjunta entre Estado e setor imobiliário, que formavam uma coalizão de interesses entorno da valorização imobiliária e representavam a vanguarda das transformações espaciais.

Partindo de uma análise histórica e teórica da periferia, procuramos mostrar o deslocamento da primazia da contradição entre capital-trabalho, sob o domínio do capital industrial, para a primazia de uma contradição urbana, sob domínio do capital financeiro, responsável pela produção de novas desigualdades.

No desenvolvimento deste artigo, inicialmente recuperamos e discutimos uma importante produção bibliográfica que problematizou a formação da periferia, interpretada como expediente de rebaixamento do custo de reprodução da força de trabalho e importante instrumento de ampliação dos ganhos na indústria, expressando dessa maneira as intensas desigualdades da urbanização brasileira.

Considerando um salto de mais de 30 anos, passamos a investigar as mudanças nas periferias das grandes metrópoles na atualidade, manifestadas pela disseminação de grandes condomínios residenciais direcionados para a população de menor renda. A atuação do setor público, por meio de uma política de financiamentos e subsídios com meta de construção de três milhões de habitações, o Programa Minha Casa Minha Vida foi decisivo na complexificação desses territórios.

Essa nova estratégia de produção do espaço, compreendida dentro de um processo de financeirização da produção imobiliária, impõe uma nova lógica de produção da periferia que faz emergir novas formas de desigualdades. São essas questões que procuramos discutir na última parte, antecedendo as considerações finais.

\section{A formação da periferia como expediente de rebaixamento da força de trabalho}

Em 1970, pela primeira vez a população urbana havia superado a rural no Brasil. ${ }^{1} 0$ rápido 
crescimento da população urbana representou ainda a consolidação de grandes aglomerados metropolitanos. Institucionalizadas em 1973, as regiões metropolitanas passam a concentrar mais da metade da população urbana (Brito e Pinho, 2012). 0 acelerado processo de urbanização no Brasil, muito superior ao dos países desenvolvidos nesse mesmo período, foi um fenômeno até então sem precedentes, diretamente relacionado ao forte crescimento industrial e seu caráter concentrador.

Entre 1940 e 1980, o PIB brasileiro cresceu com média de $7 \%$ ao ano, correspondendo ao período de maior crescimento econômico industrial brasileiro, resultante em grande medida da maior diversificação do parque industrial, com o crescimento das indústrias voltadas a bens de produção como os automóveis, principalmente concentrado no estado de São Paulo (Singer, 1968).

Conforme desenvolve Maricato (2001), as mudanças na economia brasileira influenciaram diretamente o padrão de produção da cidade, atraindo imenso contingente de população rural (dada as condições precárias de vida no campo e as dificuldades de acesso aos meios de produção), mas mantendo as intensas desigualdades que impunham à população mais pobre a moradia em áreas completamente inadequadas ao desenvolvimento urbano racional.

Nas décadas de 1950 e 1960, a cidade de São Paulo, por exemplo, registrou taxas de crescimento superiores a $5 \%$, correspondentes, no plano espacial, a um forte espraiamento da metrópole, associado em grande medida à intensa migração da população pobre. Essa expansão, viabilizada pela abertura de loteamentos populares distantes das áreas urbanizadas, ilegais em relação à legislação de uso do solo e ocupados sem qualquer infraestrutura, associou-se à percepção de um quadro crescente de problemáticas urbanas - insuficiência de transporte público, incapacidade do poder público em prover saneamento, infraestruturas e serviços urbanos para toda a cidade.

Ao procurar compreender a lógica de produção desse espaço, vários estudos acadêmicos contribuirão para o desenvolvimento de uma importante crítica ao Estado e a visão de planejamento urbano dominante, que se negava a considerar a cidade real (Tanaka, 2007). As periferias metropolitanas brasileiras foram caracterizadas de uma forma bastante precisa pela literatura sociológica e urbana nos anos 1970 e 1980.

Oliveira (1979) tem um importante papel na transposição do pensamento crítico brasileiro para o urbano, articulando a produção da periferia com as condições de super exploração da força de trabalho na industrialização. Para esse autor, o moderno (a industrialização) cresce e se alimenta do atrasado (a super exploração do trabalho); disso resulta, "a contradição, e não apenas o paradoxo, de como uma enorme massa de assalariados não chega a constituir-se um mercado para a produção capitalista, seja na residência, seja em melhoramentos urbanos" (Oliveira, 1979).

Estando a autoconstrução no cerne da produção da periferia, como forma de produção predominante, o autor destaca sua relevância como mecanismo de rebaixamento do custo de reprodução da força de trabalho:

Trata-se, também neste caso, de como se dá a produção de uma riqueza social que não é valor, que não é capital, mas é posta a serviço do capital, na medida em que 
contribua para rebaixar seja o custo da reprodução da força de trabalho, no caso da residência, seja o custo da urbanização, no caso das pequenas obras públicas feitas por moradores em seus bairros, em suas ruas. (Oliveira, 1979, p.16)

Nesse mesmo debate, Kowarick (1979) também destaca a autoconstrução como mecanismo essencial para o rebaixamento do custo de reprodução da força de trabalho. Referenciando-se nas dinâmicas de São Paulo, o autor afirma que:

A solução mais importante do ponto de vista quantitativo na cidade de São Paulo é a autoconstrução, esta magnífica fórmula que o capitalismo dependente deflagrou para rebaixar o custo da reprodução da força de trabalho, compatibilizando uma alta taxa de acumulação com salários crescentemente deteriorados. (Kowarick, 1979)

A formação da periferia é nesse sentido produto da espoliação urbana, termo definido por Kowarick (1979) como a sistemática exclusão das camadas populares do acesso aos serviços de consumo coletivo.

Os espaços periféricos são assim caracterizados como os mais distantes e de menor renda diferencial, ocupados pela população de mais baixa renda inserida de maneira mais precária no mundo do trabalho (Kowarick, 1979; Bonduki e Rolnik, 1979). Representariam territórios sem Estado, quase totalmente intocados pelas políticas públicas, exceto pelos empreendimentos habitacionais massificados, implantados a partir de finais dos anos 1960.

A expansão da periferia nas grandes cidades e mais claramente o agravamento dos processos de favelização sustentaram o fortalecimento da habitação como problema, assumindo quantitativamente a forma de um gigantesco déficit habitacional. Se durante muitos anos o rebaixamento do custo de reprodução da força de trabalho a partir da precarização da habitação vinha sendo funcional ao capital, o enfrentamento da questão habitacional revela-se como prioridade, sendo incorporado no discurso político e resultando no desenho de políticas de maior vulto.

Ao mostrar sensibilidade a um grave problema social, no qual até então a ação do Estado havia sido bastante limitada, o Governo Militar procurava assegurar o apoio da população e garantia à manutenção da ordem social. Ao mesmo tempo, ao incorporar mecanismos financeiros na expansão do crédito, suportava a expansão das empresas de construção. Em 1964, é instituído o Plano Nacional da Habitação e criado o Banco Nacional da Habitação (BNH), órgão gestor do SFH e da política habitacional.

Para Bolaffi (1979), a ampliação dos investimentos do Estado, principalmente a partir da habitação e de melhorias urbanas, consolida-se como uma importante estratégia de enfrentamento da crise. "Tudo indica, portanto que o 'problema da habitação popular'...não passou de um artifício político formulado para enfrentar um problema econômico conjuntural" (Bolaffi, 1979).

A intervenção do Estado, pautada em grandes conjuntos habitacionais periféricos impulsionaram novas frentes de desenvolvimento metropolitano, tornando mais complexa a organização desses territórios e sinalizando algumas transformações.

A partir da década de 1980, o contexto de estagnação e inflação mudou a dinâmica de 
crescimento urbano que se estruturava desde o início dos anos 1940 do século passado. No Brasil, entre 1991 e 2000, houve um aumento de $22,5 \%$ do número de favelas. Enquanto os domicílios cresceram 1,01\% em todo o país, os domicílios em favelas cresceram 4,18\%. A favela, no momento de crise, se coloca como um espaço privilegiado para reprodução da força de trabalho, por garantir acesso mais fácil ao mercado de trabalho por sua proximidade a regiões centrais (Torres e Oliveira, 2001).

Apesar do grande incremento de favelas, representando o aumento do adensamento e empobrecimento de porções mais centrais (Sempla,1990), as periferias das grandes metrópoles continuaram a crescer em ritmo muito mais acelerado que as áreas já consolidadas. Essa relação fica evidente quando se examinam as taxas de crescimento dos aglomerados metropolitanos ao longo das quatro últimas décadas. Apesar da sensível redução das taxas de crescimento populacional, a partir da década de 1980, a periferia dos núcleos metropolitanos crescerá com taxas mais elevadas repercutindo em maior incremento populacional. Essa dinâmica reafirma o padrão de urbanização extensiva - processo de incorporação horizontal de áreas rurais adjacentes aos núcleos urbanos - impondo um caráter metropolitano às nossas periferias (Torres e Oliveira, 2001).

É também a partir da década de 1980 que começa a se discutir a transformação na estrutura das cidades a partir da implantação pontual de condomínios fechados, gerando espaços onde os diferentes grupos sociais estão muitas vezes próximos, porém separados por muros e dispositivos de segurança (Caldeira, 2000).
A consolidação de grandes conjuntos habitacionais populares e o início da implantação de condomínios fechados, embora não representem processos predominantes na expansão da periferia são indicativos da ampliação da complexidade desses territórios. No contínuo processo de expansão metropolitana, essas novas dinâmicas se mesclaram ainda com retenção especulativa da terra, tida como importante estratégia para ampliação dos ganhos dos loteadores.

\section{A produção imobiliária na periferia: o Programa Minha Casa Minha Vida}

0 mercado imobiliário brasileiro historicamente foi caracterizado por seu caráter restrito, oferecendo apenas produtos de luxo, que normalmente abrangiam menos de $30 \%$ da população e estavam principalmente localizadas nas áreas mais consolidadas e valorizadas. Nesse contexto a classe média tendia a se apropriar dos recursos subsidiados utilizados na promoção pública de moradias, deixando a população de baixa renda sem alternativas, que não a ocupação de terras e a construção ilegal de suas casas. Tais dinâmicas levaram a uma massiva concentração do déficit habitacional entre as famílias mais pobres (Maricato, 2001).

A partir de 2003, com o governo Lula, é possível observar maiores esforços no sentido de construção de uma política habitacional (Cardoso et al., 2011), garantindo o direcionamento dos recursos subsidiados para a população de menor renda. 
Figura 1 - FGTS - Unidades financiadas por faixas de renda

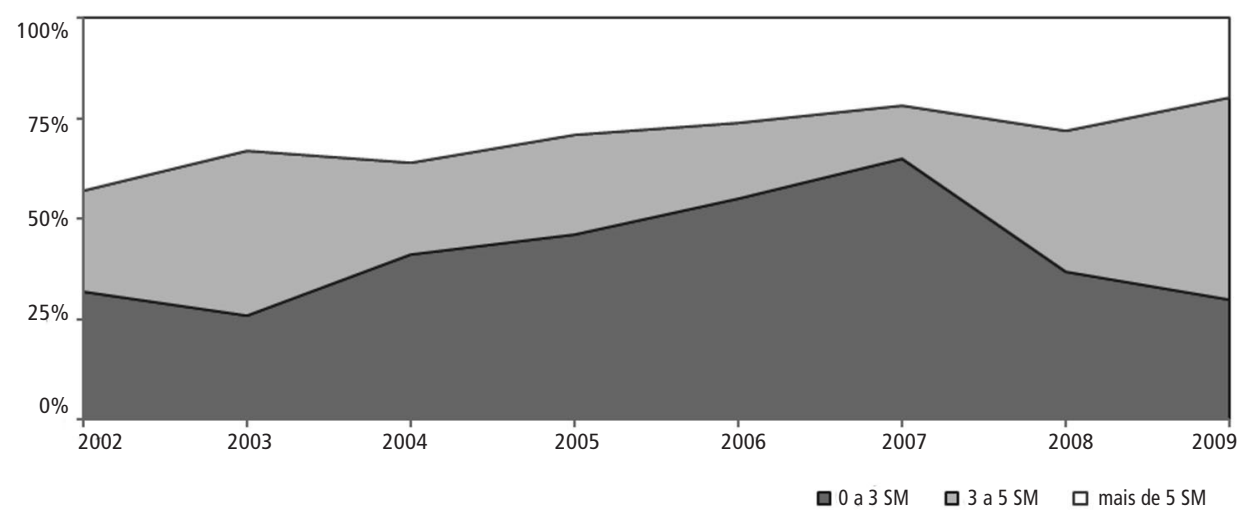

Fonte: Estatísticas Básicas do Bacen (SFH-FGTS) organizados pelo Observatório das Metrópoles.

Nesse sentido, em paralelo ao vertiginoso incremento dos fundos paraestatais, como Fundo de Garantia por Tempo de Serviço (FGTS), procurou-se garantir seu direcionamento para Habitação de Interesse Social (HIS), conforme os objetivos originais do fundo. ${ }^{2} \mathrm{~A}$ reformulação na constituição e na forma de atuação Conselho Curador do FGTS em $2003^{3}$ e as resoluções editadas principalmente a partir de $2004^{4}$ conseguiram dar maior efetividade ao direcionamento do fundo para a produção de Habitação de Interesse Social (HIS), viabilizada em vários casos pela concessão de subsídios (Royer, 2009).

Essa tendência de reforço da HIS é bastante evidente até 2007, quando $65 \%$ das unidades financiadas pelo FGTS foram direcionadas para população de até três Salários Mínimos (SM). A partir desse momento, há uma inversão dessa tendência, com o avanço da importância do financiamento para as faixas consideradas de mercado, mas ainda com rendimentos inferiores a 10 salários mínimos.

Além do direcionamento de maior parte dos financiamentos oriundos do FGTS para famílias com mais de três salários, constatou-se nesse período uma expressiva recuperação dos valores absolutos do fundo. Recuperação ainda mais evidente para o caso do FGTS. Entre 2005 e 2010, a contratação de recursos para a habitação a partir da utilização do FGTS foi multiplicado em cerca de cinco vezes, sendo esse aumento ainda mais expressivo no caso do SBPE, em que os volumes contratados em 2010 superam em mais de dez vezes as contrações do ano de 2005, como pode se observar no Gráfico 2. 
Figura 2 - Contratação de recursos para habitação SBPE/FGTS

(em R\$ bilhões)

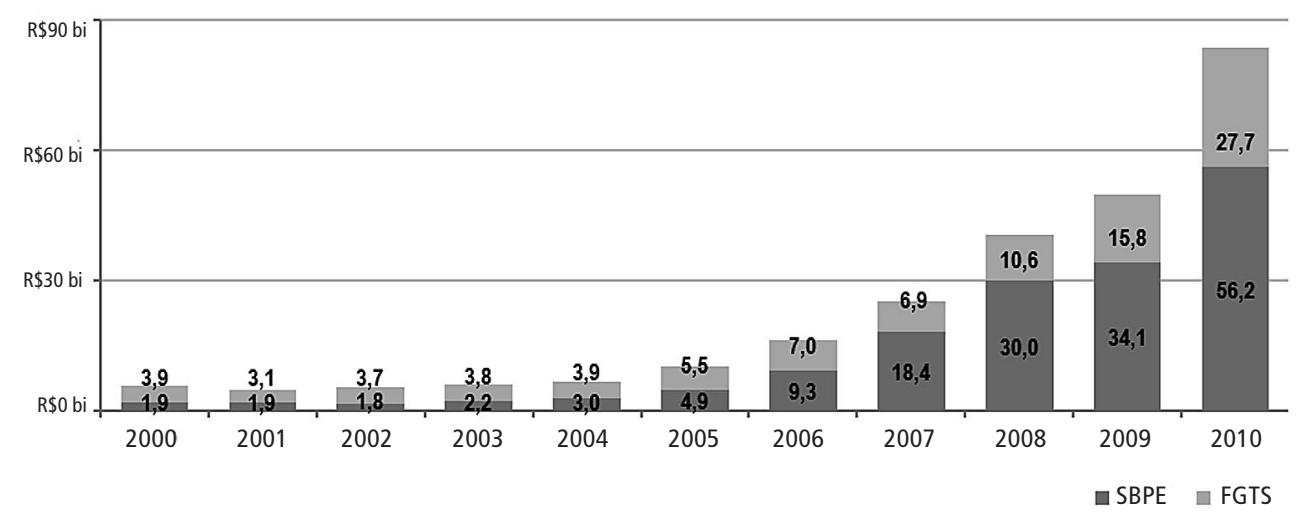

Fonte: Estatísticas Básicas do Bacen (SFH - SBPE/FGTS) organizadas pelo CBIC Dados.

Na raiz dessa mudança estariam um ambiente macroeconômico favorável e o "aprimoramento" institucional por meio da lei 10.931/2004, que ampliou a segurança jurídica do crédito imobiliário facilitando a retomada de imóveis através de instrumentos como a Alienação Fiduciária.

Com taxas de juros um pouco mais baixas, "tanto o interesse de investidores pelo mercado da construção civil pareceu aumentar, como o interesse das instituições financeiras pela concessão de crédito de longo prazo deu sinais de que essa concessão poderia ser uma atividade lucrativa" (Royer, 2009, p. 72). 0 crescimento econômico evidenciado no período ajuda a explicar o aumento da captação de recursos para esses fundos, que retomam um papel essencial no financiamento imobiliário e na expansão e diversificação do mercado imobiliário.
Shimbo (2010) ilumina com bastante clareza os processos que levaram ao crescimento exponencial de uma produção de mercado mais direcionada para a população de menor renda, mostrando os nítidos vínculos com o processo de abertura de capitais de grandes empresas de incorporação. Como a precificação das empresas no mercado de ação esteve baseada na projeção de lançamentos imobiliários a partir da propriedade da terra, a abertura de capital dessas empresas foi antecedida da consolidação de grandes bancos de terras, que se tornaram condição central para uma valorização fictícia das empresas. Segundo Shimbo (2010), no final de 2007 as empresas de capital aberto dispunham de terrenos espalhados por todo país num montante total correspondente a cerca de 37 bilhões de reais, suficientes para construir mais de 400 mil habitações (Shimbo, 2010). 
Fundados no discurso do grande déficit habitacional, na ascensão das classes C e D e na disponibilidade de financiamento no âmbito do SFH, grande parte da produção é direcionada para o chamado segmento econômico. Essas condições são exacerbadas nos relatórios de grandes consultorias internacionais e nas análises dos jornais e revistas, que apontam importantes mudanças no setor em decorrência desse direcionamento:

Esse nicho é o grande filão da indústria, tendo em vista o déficit habitacional do país, estimado em 7,2 milhões de moradias. E como já há um leque de possibilidades de financiamentos bancários a prestações baixas, os investimentos em empreendimentos econômicos não apenas se tornaram viáveis, como assumiram o status de "projetos principais" das empresas, que, agora, precisam ampliar seu portfólio para adentrar em um modelo de negócio com características peculiares e até então pouco explorado. ${ }^{5}$

Visando assegurar a ampliação dos ganhos na produção de habitação para esse segmento, evidencia-se a articulação de três estratégias fundamentais: padronização da construção, geração de economia de escala e procura de terrenos baratos. A busca pela disponibilidade de grandes glebas e terrenos mais baratos irá direcionar investimentos para as periferias, ativando as regiões das metrópoles antes não consideradas pela atuação do mercado formal.

Paradigmáticos nesse processo são os empreendimentos da empresa Bairro Novo. Originada de uma parceria celebrada em 2007 entre uma grande incorporadora nacional (Gafisa) e uma empreiteira de atuação internacional (Odebrecht), essa empresa passa a ser responsável pelo lançamento de grandes condomínios/bairros imobiliários em periferias metropolitanas de várias regiões do Brasil, desenvolvendo em grandes glebas empreendimentos semelhantes que passam a reunir até mais de 5.000 unidades.

Nesse momento fica evidente a associação entre a intensificação de uma produção residencial massificada em áreas periféricas e 0 processo crescente de centralização do capital nas grandes empresas de incorporação - que se consolidam como as principais beneficiadas do projeto de articulação entre Mercado Imobiliário e Estado, proposto no início da década de 2000, quando fora lançado o Projeto Moradia. Concebido como um dos projetos de desenvolvimento para o país na campanha de Lula, a proposta visava associar o enfrentamento da questão social a crescimento e geração de empregos, considerando para isso a ativação do mercado imobiliário. Como explicita Bonduki (2009) "para concentrar o FGTS na baixa renda, seria indispensável a retomada da produção habitacional pelo mercado, para atender a classe média, reativando o crédito imobiliário, particularmente do SPBE (recursos da poupança), que não vinha cumprindo os dispositivos legais que exigem a aplicação dos seus fundos em habitação, pois o governo $\mathrm{FHC}$, baseado no rigor monetarista, enxergava o financiamento habitacional como inflacionário".

Na sequência da ativação da produção imobiliária para setores anteriormente não atendidos pelo mercado, evidencia-se uma forte aliança "entre movimentos de luta pela moradia e setores empresariais representados no Conselho Nacional das Cidades" (Santo Amore, 2015, p. 16). Essa aliança é oficializada com o lançamento da Campanha Nacional pela Moradia Digna - uma prioridade social, ${ }^{6}$ 
"cuja meta era a aprovação de uma Proposta de Emenda Constitucional (PEC) que vinculasse $2 \%$ dos recursos orçamentários da União e $1 \%$ dos estados, Distrito Federal e municípios aos seus respectivos Fundos de Habitação de Interesse Social, lastreando permanentemente a política nacional de produção habitacional" (Santo Amore, 2015).

No contexto de lançamentos grandiosos e de avanço de articulação de setores e grupos antes vistos como rivais, a crise internacional de 2008 colocou em ameaça a liquidez dos grandes empreendimentos em construção, impondo ainda sérias dificuldades financeiras às grandes empresas que naquele momento detinham grande soma de investimentos imobilizados em bancos de terra.

Nesse momento, a retórica da importância da atividade da construção imobiliária foi reforçada, seja pelo seu papel na provisão de novas habitações contribuindo na solução do 'déficit habitacional', seja como motor de reativação da economia nacional, legitimando a condução de massivos esforços para ampliação dos financiamentos e subsídios ao setor. Esses esforços ganharam status de Programa habitacional e de política anticíclica, com o lançamento do Programa Minha Casa Minha Vida (MCMV) em março de 2009 e a promessa de produção de um milhão de casas. Em junho de 2011, foi lançada a segunda etapa do Programa, considerando agora a construção de mais dois milhões de habitações.

0 socorro questionável prestado pelo Governo Federal, por meio do lançamento do Programa MCMV, garantiu a solvência do estoque construído, reforçou a valorização das ações das grandes empresas do setor e deu fôlego para a retomada do crescimento da produção, reforçando a expansão da produção do segmento econômico dos grandes grupos imobiliários.

Com o objetivo de criar condições de ampliação do mercado habitacional para atendimento das famílias com renda de até 10 SM, o Programa MCMV estabeleceu um conjunto de subsídios proporcionais à renda das famílias. Além dos subsídios, o Programa garantiu o aumento do volume de crédito para aquisição e produção de moradias, a redução de juros, e segurança ao negócio imobiliário a partir da criação do Fundo Garantidor da Habitação - que aporta recursos para pagamento das prestações em caso de inadimplência por desemprego e outras eventualidades (Cardoso et al., 2011).

Segundo dados do Ministério das Cidades, nos últimos quatro anos foram investidos mais 190 bilhões de reais, considerando os subsídios diretos e linhas de crédito disponibilizadas. Esses recursos foram responsáveis pela contratação 2.980.177 unidades imobiliárias em todo o Brasil. 0 Programa está atualmente dividido em três faixas de renda $(1,2,3)$. Na faixa 1 , que abrange as famílias com renda até 1.600 reais, os subsídios podem chegar até $96 \%$, dependendo da renda da família. Nesta faixa o crédito disponibilizado para as famílias deve ser pago em 10 anos. Na faixa de 2, os subsídios podem chegar até 25.000 reais e 0 crédito disponibilizado deve ser pago em 30 anos. Na faixa 3, não existe subsídios diretos, mas cumpre lembrar que os juros do crédito disponibilizado são bastante inferiores aos do mercado, e conta-se ainda com isenção de taxas e impostos.

No desenho do Programa MCMV, as grandes empresas participaram de maneira 
decisiva, tornando-se protagonistas em sua implementação. A importância dessas grandes empresas pode ser também mensurada pela grande concentração da produção por um número pequeno de grandes empresas. Uma análise de uma amostra específica dos empreendimentos contratados até agosto de 2012, revelou que apenas dez empresas participaram da produção de cerca de $44 \%$ das unidades produzidas. Dessas dez empresas, seis tinham capital aberto na bolsa de valores.

No Programa cabe ao mercado a promoção dos empreendimentos imobiliários, elaborados de acordo com as exigências técnicas mínimas estabelecidas pela Caixa Econômica Federal (CEF), responsável pela gestão e operacionalização do PMCMV. 0 papel dos estados e municípios, nesse modelo, passou a ser o de organizar a demanda para a faixa de menor renda (faixa 1) e criar condições complementares para facilitar a produção em todas as faixas, através da desoneração tributária e da flexibilização da legislação urbanística e edilícia dos municípios (Cardoso et al., 2011). Para as demais faixas, os imóveis são disponibilizados no mercado para compradores que se adequem ao perfil do Programa.

Mesmo prevalecendo o discurso da finalidade social do Programa, a distribuição dos recursos entre as diferentes faixas de renda tendeu a privilegiar os produtos direcionados a faixas de maior renda nas quais a atuação das grandes empresas nacionais de incorporação era mais dominante. Embora o déficit para as faixas 2 e 3 juntas correspondesse a $23,5 \%{ }^{7}$ do total do déficit em $2007,55 \%$ das unidades contratadas até abril de 2013 foram destinadas para as famílias nessas faixas.
Como os preços finais estão pré-determinados pelos tetos estabelecidos para as diferentes faixas, a maximização dos ganhos do setor privado continua a ser garantida pela redução do custo de construção e do preço da terra. A necessidade de redução de custos de construção reforçou os esforços em curso no sentido de padronização, industrialização e ampliação da escala dos empreendimentos.

Apesar de inicialmente o PMCMV ter definido como limite máximo para cada empreendimento a construção de 500 unidades habitacionais ou condomínios segmentados em até 250 habitações, o que se verificou foi a consolidação de grandes blocos, acomodando mais de mil unidades (Cardoso et al., 2011). A partir de 2011, o Programa passa a permitir empreendimentos de até 1.500 unidades, e em 2012, esse máximo é elevado para 5.000 unidades. Embora tenham sido constantes alguns esforços no sentido de assegurar condições mínimas de qualidade dos empreendimentos, a partir da edição das sucessivas normativas do Programa, o que parece prevalecer são as estratégias de ampliação dos ganhos por parte das empresas. Quando se analisa a localização da produção dos empreendimentos Minha Casa Minha Vida nas regiões metropolitanas, verifica-se a predominância da localização dos empreendimentos fora dos municípios-polo, mostrando desarticulação do ProgramaPrograma com a concentração dos déficits e políticas habitacionais locais. Embora no Brasil praticamente não exista planejamento na esfera metropolitana, o Programa legitimou a metropolização do déficit, permitindo que os empreendimentos fossem implementados nos municípios mais distantes do núcleo, assegurando maiores ganhos ao setor privado. 
Até agosto de $2011{ }^{8}$ das cerca de 440.000 unidades contratadas pelo Programa nas Regiões Metropolitanas, cerca de $57 \%$ estavam localizadas nos municípios da periferia metropolitana. Para os empreendimentos da faixa 1, essa tendência é ainda mais forte. Nessa faixa, cerca de $65 \%$ dos empreendimentos construídos pelo Programa estão localizados nos municípios mais periféricos das Regiões Metropolitanas. Nesses municípios o recebimento de grandes empreendimentos habitacionais é visto como alternativa de dinamização econômica, substituindo o papel outrora desempenhado pela indústria, e fonte de imensos ganhos políticos ao possibilitar um grande número de unidades de HIS, anteriormente inviabilizadas pela dependência de recursos municipais. Nesse sentido, se justificam amplas isenções fiscais, recomendadas nas normativas do Programa, e flexibilização dos instrumentos urbanísticos.

Estudos mais recentes, que apresentam com precisão a localização geográfica desses empreendimentos em regiões metropolitanas específicas, como Rio de Janeiro, Fortaleza e Belém (Cardoso et al., 2011; Pequeno, 2013; Lima et al., 2013), mostram ainda que o fato de parte desses empreendimentos estar localizada no município-polo não assegura condições de localização satisfatórias. Nesses municípios, prevalece a localização em áreas precárias e periféricas, onde já se localizavam grandes loteamentos populares, conjuntos habitacionais e favelas. Assim, os empreendimentos do Programa, além de abrirem frentes pioneiras de urbanização, têm contribuído para 0 adensamento de áreas periféricas, apropriando-se de grandes lotes remanescentes. A apropriação de novas áreas e dos tecidos existentes tem, entretanto, caráter seletivo, associando basicamente dois aspectos principais: menor custo da terra e disponibilidade de alguma infraestrutura de mobilidade. Tal seletividade tende a reforçar uma metropolização linear, ao longo dos eixos e infraestruturas de mobilidade existentes, tornando mais custosa a implementação de infraestruturas e ampliando a distância dos moradores aos locais de emprego.

Com a produção simultânea de empreendimentos para as diferentes faixas, a faixa 1 é direcionada para as piores localizações na metrópole. Como o Programa não previu, em sua primeira etapa, a construção de equipamentos públicos, essas áreas, mesmo produzidas a partir de relações capitalistas avançadas, surgem com carências de equipamentos públicos e permanecem sem acesso a comércios e serviços, os quais muitas vezes passam a ser oferecidos por meios informais.

Embora existam particularidades regionais, um dos resultados claros do Programa é o esgarçamento das periferias, consolidando o alargamento e a metropolização da produção imobiliária, disseminando a valorização imobiliária em áreas que até então não haviam sido objeto de investimentos imobiliários.

0 horizonte desse processo parece ser a extensão de uma urbanização segregada e privada (Lencioni, 2003) às periferias, multiplicando sociabilidades restritas a grandes condomínios que oferecem como áreas coletivas espaços precários e pouco apropriados por seus moradores.

Até janeiro de 2014, o Programa Minha Casa Minha Vida já havia contratado mais de 3,2 milhões de moradias, tendo sido entregue 1,51 milhão de unidades. 


\section{Novas periferias ou novas formas de produção de desigualdades?}

A partir dos anos 1990, um conjunto de novos estudos passa a revelar o sensível avanço de investimentos do Estado nas periferias, principalmente nas áreas de saneamento e educação, além dos investimentos pontuais em pavimentação das ruas locais (Marques e Bichir, 2001). Muitos dos avanços alcançados podem ser vistos como resultado da crescente organização dos movimentos sociais, que emergem do contexto de precariedade e ausência dos bens de consumo coletivo, e passam a reivindicar pelo direito à cidade.

Para Torres e Oliveira (2001), a presença desses serviços não significa que as desigualdades tenham sido eliminadas, manifestando-se por outras dimensões menos óbvias, como a ausência ou precariedade de emprego, aumento dos níveis de violência e maior distância dos equipamentos de saúde, entre outros aspectos (Torres e Oliveira, 2001). Nessa mesma periferia também passam a se reconhecer novas desigualdades, manifestadas pelas "favelas de periferia" e ampliação das moradias em situação de risco ambiental.

Embora o crescimento das favelas tenha sido interpretado como consequência de um cenário de crise, configurado a partir dos anos 1980 e resultando no adensamento e empobrecimento de porções mais centrais, 0 que passa a se verificar a partir da década de 1990 é a emergência das favelas na periferia, dando origem a um fenômeno da "hiperperiferia" (Torres e Marques, 2001, apud Torres e Oliveira, 2001), muitas vezes associadas a riscos ambientais. "Áreas de inundação, sujeitas a deslizamentos, localizadas próximas a aterros de lixo e junto a depósitos de resíduos tóxicos caracterizam, muitas vezes, as mais precárias condições residenciais da periferia metropolitana, onde diversas situações de desigualdades e risco se sobrepõem" (Torres e Oliveira, 2001). Esses processos revelam a imposição de crescentes dificuldades de acesso à moradia pelos mais pobres, reforçando a importância da propriedade privada da terra mesmo em áreas mais periféricas.

0 reconhecimento de novas estratégias de reprodução do capital, manifestada pelo avanço das relações capitalistas na produção imobiliária na periferia, indica importantes transformações no processo de urbanização, sinalizando novas relações com o processo de industrialização. De fato, a produção de uma "nova periferia" não se articula mais a um acelerado crescimento industrial, pelo contrário, pode ser vista como um importante meio de dinamização da economia em si. Para Volochko (2011), já a partir da década de 1980, fica mais claro um descolamento da questão habitacional e da problemática industrial, dando relevo à urbanização como processo autônomo e dominante, não mais diretamente relacionado à industrialização (Pereira, 2005).

Se antes a indústria estava presente como um forte elemento de atração dos trabalhadores, a nova lógica de produção imobiliária financeirizada repõe a importância industrial visando uma verdadeira fabricação habitacional, que segue escalas e métodos crescentemente industrializados e se apoia na retórica de um déficit habitacional como poder de barganha de seus interesses e estratégias (Volochko, 2011). A partir de uma ação do Estado, manifestada 
pela implementação do Programa MCMV, essa lógica é estendida e legitimada.

Nesse Programa, uma ampla convergência de interesses entre agentes públicos e privados, acaba por reforçar o movimento de confluência do capital financeiro à produção imobiliária (Fix, 2012). Essa aproximação resultará por vezes em arranjos em que a frágil correlação de forças entre os agentes envolvidos (grandes empresas versus prefeituras municipais) favorecerá a imposição de um padrão de produção imobiliária que preconiza ampliação crescente dos ganhos na reprodução do capital no espaço. Esse padrão se sobreporá a condições extremamente desiguais de desenvolvimento urbano das cidades brasileiras, que, por influír no preço da terra, são determinantes na definição das estratégias da produção do espaço.

Aqui cabe lembrar que esse movimento, antes de encontrar a propriedade privada da terra como obstáculo, a potencializa como condição à sobrevida do capitalismo, concretizando as reflexões de Lefebvre sobre a centralidade da propriedade privada (2008, p. 160):

Longe de constituir um obstáculo ao crescimento no quadro do capitalismo, ela foi seu ponto de apoio, e, entretanto, ela destina esta sociedade a um caos espacial sobre o qual peço que thes reflitam...

A disseminação dessa lógica de produção às periferias faz com que a expansão da produção imobiliária capitalista aconteça em muitos casos dissociada das condições gerais de urbanização, antes tidas como determinantes para viabilização de empreendimentos imobiliários. Nessa lógica, qualquer terreno adquire potencial para a valorização do capital. Na fala de um empresário do setor imobiliário, "Não existe terreno ruim. Tem terreno caro e terreno juridicamente incomprável [sic]. Qualquer terreno você viabiliza um empreendimento, por mais popular que ele seja". Impõe-se, assim, uma grande fluidez ao valor da terra, que assume sua condição potencial de ativo financeiro.

Pelo desenho do Programa, o conflito mais latente, da órbita que envolvia a empresa de construção e os proprietários fundiários, é deslocado para o âmbito do Estado, que pela elevação sucessiva dos valores limites das unidades e flexibilização das normas de uso e ocupação, passa a legitimar o aumento do preço da terra e apropriações de áreas cada vez mais precárias.

A ausência de equipamentos, comércios e serviços e a grande distância a áreas que concentram empregos são minimizadas pela satisfação da propriedade privada da casa, modalidade exclusiva de acesso à habitação no âmbito do Programa MCMV. Essa disseminação da propriedade privada, associada a sua intensa valorização, permite ao governo federal contabilizar o aumento do capital residencial como um dos resultados mais positivos do Programa ${ }^{9}$ exaltando e legitimando a valorização imobiliária.

Essa valorização imobiliária vem sustentando imensos ganhos às empresas e aos proprietários de terra. De acordo com ranking da consultoria Economatica, no terceiro trimestre de 2009, estavam no Brasil 12 das 20 construtoras de capital aberto mais lucrativas da América Latina e Estados Unidos.

Por outro lado, a capacidade de realização do valor desses imóveis para seus proprietários é limitada. Primeiro, porque pelas condições estabelecidas pelo Programa, a 
população beneficiada com os maiores níveis de subsídios só poderá realizar a venda legal desses imóveis após dez anos. Segundo, porque a baixa qualidade construtiva e rápida obsolescência desses grandes empreendimentos, constatada por pesquisas e reportagens em diferentes meios de comunicação, põe em questão a capacidade de venda desses móveis pelos preços indicados no mercado. Esses entraves, entretanto, não vêm impedindo a continuidade de práticas de vendas irregulares, normalmente feitas a preços bastante inferiores aos praticados no mercado. Além disso, a seleção dos beneficiários do Programa vem sendo objeto de alguns questionamentos.

Os impactos da disseminação dessa lógica de produção sobre as periferias não se restringem aos proprietários, tende ainda a promover novas formas de desigualdades, à medida que dificulta a produção de habitação mais acessível e entrava o seu acesso por outros meios de produção, que permanecem a acontecer com maior precariedade. Essa contradição, levada à periferia, tende a extinguir as condições de acesso à moradia dos mais empobrecidos na cidade. Nesse sentido, as desigualdades se impõem com maior força entre os mais empobrecidos e não beneficiados por essa lógica de disseminação da propriedade imobiliária.

Tal contradição se explicita nas limitações do Programa MCMV na resolução do problema que se propõe resolver - o déficit habitacional. Quando se observa a evolução do déficit entre 2008 (ano que antecede a implementação do Programa) e 2012, constata-se que esse avançou de 5.191 .565 domicílios para 5.244.525, representando um acrescimento absoluto de 52.960 domicílios (IBGE-PNAD 2007-2012). A redução relativa do déficit nesse período, de $9 \%$ para $8,53 \%$, deve-se, entretanto, ao contexto de intensificação da produção imobiliária, com aumento significativo do número total de domicílios.

Os resultados do Programa podem ser questionados principalmente quando se examina com maior cuidado a distribuição do déficit entre as diferentes classes e entre seus componentes. ${ }^{10}$ Em 2008, 70,2\% do déficit estava concentrado entre a população de até três SM. Essa proporção avançou para 73,6\% em 2012. Para essa faixa de renda, o aumento absoluto do déficit foi 215.492 domicílios.

Cumpre ressaltar que o déficit brasileiro é essencialmente urbano. Em 2012, 85\% do déficit estava concentrado nas áreas urbanas. Foi justamente nessas áreas que o déficit habitacional apresentou maior aumento absoluto, com ampliação de cerca de 224.000 domicílios.

Quando se avaliam os componentes desse déficit urbano, é importante reconhecer que houve um importante avanço na resolução das situações de precariedade, que representavam cerca de $12 \%$ do déficit em 2008 e passaram a representar 8\% do déficit em 2012 (ver Figura 3). Por outro lado, houve um importante avanço do déficit relacionado ao ônus excessivo com aluguel, que representava 40\% em 2008 e passou a representar cerca de 50\% em 2012. Cumpre lembrar que a componente "ônus excessivo de aluguel", que corresponde às situações em que as despesas com o aluguel são superiores ou igual a $30 \%$ do orçamento familiar, só incluem domicílios com renda total de até três salários mínimos. 
Figura 3 - Distribuição do Déficit habitacional por componente (urbano)\%

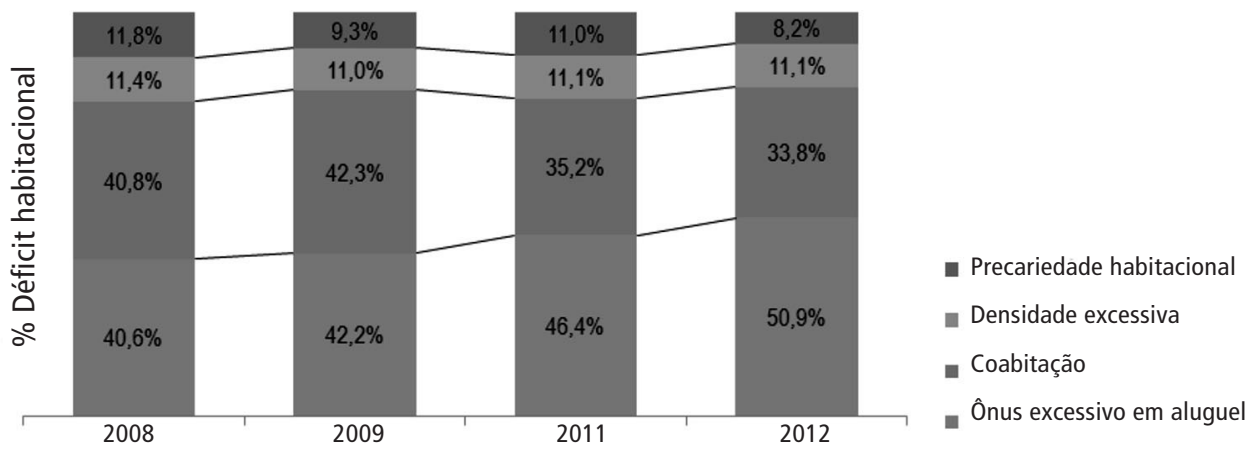

Fonte: Estatísticas Básicas do Bacen (SFH-SBPE/FGTS) organizadas pelo CBIC Dados.

Esses números iluminam com clareza os aspectos contraditórios do avanço das relações capitalistas sobre na produção do espaço. Se por um lado, pode-se perceber a superação de parte das situações de precariedade, caracterizadas por domicílios produzidos com materiais precários e normalmente autoconstruídos, 0 avanço do déficit por ônus excessivo de aluguel é muito mais expressivo.

Nesse sentido, a produção imobiliária da periferia não pode ser compreendida de maneira isolada, inserindo-se em todo o movimento de ampliação da valorização imobiliária da metrópole, que por sua vez reforça os deslocamentos para a periferia e influencia também a valorização do estoque já construído, elevando os aluguéis de maneira geral. Essa dinâmica explica o significativo avanço do ônus excessivo por aluguel.

Na cidade de São Paulo, entre janeiro de 2008 e janeiro de 2014, os aluguéis tiveram um aumento médio de 96,2\%. No Rio de Janeiro, esse aumento foi ainda maior, tendo os aluguéis aumentado, em média, 138\% (dados Fipe-Zap). Esses aumentos foram significativamente superiores à inflação, que no referido período foi de 43,2 \% (IGPM).

A disseminação de uma lógica estritamente capitalista vem contraditoriamente reforçando processos antigos, como as ocupações. As mobilizações de junho de 2013, que trouxeram em suas raízes reivindicações urbanas, fizeram disparar na cidade de São Paulo as ocupações, em resposta a essa lógica que impõe o afastamento contínuo dos mais pobres das cidades.

\section{Considerações finais}

Embora a força do termo periferia permaneça presente nas leituras da metrópole contemporânea, o que se evidencia na atualidade é um esvaziamento da carga teórica que o constituiu (Tanaka, 2007). Grande parte das interpretações da época partia da análise da relação 
entre os processos de urbanização e de industrialização, os quais tendiam a promover graves desequilíbrios socioespaciais. 0 reconhecimento de dinâmicas diferenciadas, que já aparecem desde finais da década de 1980 e são reforçadas com o avanço de uma produção imobiliária nesses territórios na atualidade, impõe o desafio de uma atualização teórica, que considere uma nova lógica de produção do espaço e as novas formas de produção de desigualdades.

A busca contínua de oportunidades para a valorização imobiliária, representada pela incorporação de novos espaços e pela intensificação da ocupação dos espaços existentes, define 0 atual processo de crescimento da metrópole e reforça o espaço como raridade. A generalização dessa nova lógica de produção do espaço encontrará nas bordas das metrópoles um espaço marcado por grande desigualdade que se expressa em extremos como a apropriação de espaços públicos por moradias precárias e a forte retenção especulativa da terra.

A produção imobiliária organizada na metrópole por um nível de centralização do capital muito mais elevado tende a tornar a estrutura urbana ainda mais desigual e segregada. Parte da enorme rentabilidade obtida pelo setor imobiliário é alcançada a partir da reprodução da segregação herdada e da histórica valorização imobiliária dessa estrutura desigual, que se dá pela contínua redefinição da segregação e elevação do gradiente de preços. As diferenças entre áreas centrais, mais caras, e as periféricas, mais baratas, continuarão existindo, mas serão redefinidas e multiplicadas pela fragmentação, numa hierarquização socioespacial que ora aproxima, ora distancia as atividades urbanas e os grupos sociais.

De certa maneira, há uma substituição da ideia anteriormente preponderante do espaço urbano como condição de reprodução do capital (industrial em geral) para a de que o objetivo é, imediatamente, a produção do espaço, passando a ocorrer, então, uma subordinação direta do espaço ao investimento industrial (imobiliário) e à reprodução do capital, como problematizou Lefebvre:

0 processo que subordina as forças produtivas ao capitalismo se reproduz aqui, visando à subordinação do espaço que entra no mercado para o investimento dos capitais, isto é, simultaneamente 0 lucro e a reprodução das relações de produção capitalistas. Os lucros são imensos e a lei (tendencial) de queda da taxa de lucro médio é muito eficazmente bloqueada. (Lefebvre, 1999, p. 164)

Se, originalmente, as periferias eram interpretadas como a resultante da contradição entre capital trabalho no curso do processo de industrialização, sua análise na atualidade revela a primazia de uma contradição urbana que se exprime na totalidade da produção do espaço. 0 avanço de uma nova lógica de produção nesses espaços tende a exacerbar a reprodução do capital em detrimento das necessidades da reprodução social. É nesse sentido que toma força uma contradição urbana, representada pela transição de uma produção urbana entendida como meio para a reprodução das relações sociais para uma hegemonia da produção imobiliária, representada pela privatização do espaço e do valor. 


\section{Maria Beatriz Cruz Rufino}

Universidade de São Paulo, Faculdade de Arquitetura e Urbanismo. São Paulo/SP, Brasil. beatrizrufino@usp.br

\section{Notas}

(1) De acordo com dados do Censo/IBGE, 1970.

(2) O Fundo de Garantia por Tempo de Serviço foi criado pela Lei n. 5107/66, como um fundo indenizatório que garantisse uma reserva de recursos para a manutenção do trabalhador durante os períodos de desemprego, que, já se previa, se tornariam mais frequentes com a flexibilização das relações de trabalho decorrentes das mudanças na Consolidação das Leis do Trabalho. O fundo foi formado com a poupança compulsória de $8 \%$ dos salários mensais recolhidos pelo empregador sobre as folhas de pagamento, acumulando um montante que foi usado pelo Estado para financiar investimentos nos setores sociais como Habitação e Saneamento, mas também na infraestrutura (Castro, 1999, p. 74).

(3) Em 2003, após a criação do Ministério das Cidades, esse passou a ser o responsável pela gestão da aplicação dos recursos do Fundo, tendo, entre outras atribuições, "a de estabelecer metas a serem alcançadas nos Programas de habitação popular, saneamento básico e infraestrutura urbana" (Royer, 2009, p. 87).

(4) Com destaque para a Resolução no 460 do CCFGTS, de 14 de dezembro de 2004, que "garantiu $60 \%$ dos recursos de aplicação do FGTS para a área de habitação popular, de acordo com a lei $8.036 / 90,30 \%$ para saneamento básico, $5 \%$ para infraestrutura urbana e $5 \%$ para operações especiais (percentual progressivamente reduzido até sua extinção a partir de 2008)" (Royer, 2010, p.87). A resolução 460 também foi responsável pela constituição de um novo modelo de subsídios "permitindo que os recursos do Fundo alcançassem efetivamente a população de mais baixa renda, até um salário mínimo" (Royer, 2009, p. 88). Essa resolução permitiu ainda a ampliação das aplicações globais dos recursos, que atingiram o montante de R\$4.447.337 mil, em 2005 (Relatório de Gestão do FGTS do ano de 2006, apud Royer, 2009, p. 88).

(5) Reportagem "O assédio das grandes" na revista Construção Mercado n. 79, de fevereiro de 2008.

(6) Ver histórico da Campanha na página da internet, disponível em: http://www.moradiadigna.org. $\mathrm{br} /$ moradiadigna/v1/index2.asp?p=11. Acesso em: maio 2015.

(7) De acordo com dados do IBGE/PNAD 2007.

(8) De acordo com dados do Ministério das Cidades.

(9) De acordo com o Sumário Executivo da Pesquisa "Casa Própria: Capital Residencial e Qualidade de Vida". Desenvolvida pelo Ipea, 2013.

(10) Habitações precárias, coabitação familiar, ônus excessivo com aluguel e adensamento excessivo em domicílios locados. 


\section{Referências}

BOLAFFI, G. (1979). "Habitação e urbanismo: o problema e o falso problema". In: MARICATO, E. A produção capitalista da casa (e da cidade) no Brasil Industrial. São Paulo, Alfa-omega.

BONDUKI, N. (2004). Origens da habitação social no Brasil Arquitetura Moderna, Lei do inquilinato e Difusão da Casa Própria. São Paulo, Estação Liberdade.

(2009). Do Projeto Moradia ao Programa Minha Casa Minha Vida. Revista Teoria e Debate, n. 82.

BONDUKI, N. e ROLNIK, R. (1979). Periferias: ocupação do espaço e reprodução da força de trabalho. São Paulo, Fundação para Pesquisa Ambiental.

BRITO, F. A. e PINHO, B. A. T. D. (2012). A dinâmica do processo de urbanização no Brasil, 1940-2010. Texto para discussão, 464. Belo Horizonte, UFMG/Cedeplar.

CALDEIRA, T. P. (2000). Cidade de muros: crime, segregação e cidadania em São Paulo. São Paulo, Edusp/Editora 34.

CARDOSO, A. L.; ARAGÃO, T. A. e ARAUJO, F. S. (2011). Habitação de interesse social: política ou mercado? Reflexões sobre a construção do espaço metropolitano. XIV ENCONTRO NACIONAL DA ANPUR. Anais. Rio de Janeiro.

CASTRO, C. M. P. de (1999). A explosão do autofinanciamento na produção da moradia em São Paulo nos anos 90. Tese de Doutorado. São Paulo, Universidade de São Paulo.

FIX, M. A. B. (2012). Financeirização e transformações recentes no circuito imobiliário no Brasil. Tese de Doutorado. Campinas, Universidade Estadual de Campinas.

GOTTDIENER, M. (2007). A produção social do espaço urbano. São Paulo, Edusp.

KOWARICK, L. (1979). A espoliação urbana. Rio de Janeiro, Paz e Terra.

LEFEBVRE, H. (1999). A revolução urbana. Belo Horizonte, Editora UFMG. (2008). Espaço e política. Belo Horizonte, Editora UFMG.

LENCIONI, S. (2003). "Uma nova determinação do urbano: o desenvolvimento do processo de metropolização do espaço". In CARLOS, A. F. A. e LEMOS, A. I. G. (orgs.). Dilemas urbanos: novas abordagens sobre a cidade. São Paulo, Contexto.

LIMA, J. R.; PONTE, J. P. X.; RODRIGUES, R. M.; VENTURA NETO, R. e MELO, A. C. C. (2013). “A promoção habitacional através do Programa Minha Casa Minha Vida na Região Metropolitana de Belém". In: CARDOSO, A. L. et al. O Programa Minha Casa Minha Vida e seus Efeitos Territoriais. Rio de Janeiro, Letra Capital.

MARICATO, E. (2001). Brasil, Cidades: alternativas para a crise urbana. Petrópolis, Vozes.

MARQUES, E. e BICHIR, R. (2001) Investimentos públicos, infraestrutura urbana e produção da periferia em São Paulo. Revista Espaço e Debates. São Paulo, Neru, v. XVII, n. 42.

MENDONÇA, M. J. e SACHSIDA, A. (2012). Existe bolha no mercado imobiliário brasileiro? Texto para discussão, 1762. Brasília, Ipea.

OLIVEIRA, F. (1979). "Prefácio". In: MARICATO, E. (org.). A produção capitalista da casa (e da cidade) no Brasil industrial. São Paulo, Alfa-omega. 
PEQUENO, L. R. B. (2013). Minha Casa Minha Vida em Fortaleza: novas periferias? XIV ENCONTRO NACIONAL DA ANPUR. Anais. Recife.

PEREIRA, P. C. X. (2005). Dinâmica imobiliária e metropolização: a nova lógica do crescimento urbano em São Paulo. Scripta Nova. Barcelona, v. 10, n. 194.

ROCHA LIMA JR., J. e GREGÓRIO, C. A. G. (2008). Valuation e Investimento nas ações das empresas de Real Estate no Brasil: cenário do ciclo de captação Intensiva (2005-2007). VIII LATIN AMERICAN REAL ESTATE SOCIETY (LARES) INTERNATIONAL SEMINAR. Anais. São Paulo.

ROYER, L. de O. (2009). Financeirização da política habitacional: limites e perspectivas. Tese de Doutorado. São Paulo, Universidade de São Paulo.

RUFINO, M. B. C. (2012). A incorporação da metrópole: centralização do capital no imobiliário e nova produção do espaço em Fortaleza. Tese de Doutorado. São Paulo, Universidade de São Paulo.

SANTO AMORE, C. (2015). “Minha Casa Minha Vida” para iniciantes. In: SANTO AMORE, C.; SHIMBO, L. Z. e RUFINO, M. B. C. (orgs.). Minha Casa... E a Cidade? Avaliação do Programa Minha Casa Minha Vida em seis estados Brasileiros. Rio de Janeiro, Letra Capital.

SEMPLA (1990). São Paulo: crise e mudança. São Paulo, Brasiliense.

SHIMBO, L. Z. (2010). Habitação Social, Habitação de mercado: a confluência entre estado, empresas construtoras e capital financeiro. Tese de Doutorado. São Carlos, Universidade de São Paulo.

SINGER, P. I. (1968). Desenvolvimento econômico e evolução urbana. São Paulo, Cia. Editora Nacional.

TANAKA, G. M. M. (2006). Periferia: conceito, práticas e discursos. práticas sociais e processos urbanos na metrópole de São Paulo. Dissertação de Mestrado. São Paulo, Universidade de São Paulo.

TORRES, H. G. e MARQUES, E. (2001). Reflexões sobre a hipetrofia: novas e velhas faces da pobreza no entorno metropolitano. Revista Brasileira de Estudos Urbanos e Regionais, n. 4

TORRES, H. G. e OLIVEIRA, M. A. (2001). Quatro imagens da periferia paulistana. Revista Espaço e Debates. São Paulo, Neru, v. XVII, n. 42.

VOLOCHKO, D. (2011). Novos espaços e cotidiano desigual nas periferias da metrópole. Tese de Doutorado. São Paulo, Universidade de São Paulo.

Texto recebido em 25/maio/2015

Texto aprovado em 4/out/2015 